\title{
Competencias docentes: Desde la opinión de los profesores de programas de pregrado en psicología
}

\section{Teaching Competencies: From the opinion of professors of undergraduate psychology programs}

\author{
Andrés Felipe Rojas Zapata \\ Magíster en Docencia Universitaria, miembro del Grupo de Investigación: Convivencia y entornos psicológicos CONEPSI \\ Coordinador de Investigaciones - Corporación Regional de Educación Superior CRES, sede Pasto. \\ Correspondencia: andresps0707@hotmail.com \\ Universidad de Nariño, Nariño, Colombia \\ Isabel Hernández Arteaga \\ Pos-doctora en Investigación Cualitativa \\ Doctora en Ciencias de la Educación \\ Miembro Centro de Investigaciones en Docencia Universitaria - CIDU \\ Docente investigadora de la Escuela de Posgrados en Educación \\ Correspondencia: isabel.hernandez@ucc.edu.co \\ Universidad Cooperativa de Colombia sede Bogotá, Tunja, Colombia
}

Recibido: 13 de febrero de 2017. Aprobada: 18 de mayo de 2017

Cómo citar este artículo:

Rojas, A. y Hernández I. (2017). Competencias docentes: Desde la opinión de los profesores de programas de pregrado en psicología. Espiral, Revista de Docencia e Investigación, 7(2), 95 - 106.

\section{Resumen}

El presente artículo es producto de la investigación que se obtuvo como resultado de la tesis "Competencias docentes para profesores de programas de pregrado en psicología".

Objetivo. Determinar la concepción sobre competencias docentes que subyace en los profesores de programas de pregrado en psicología.

Metodología. La investigación se orientó desde el paradigma cualitativo de la investigación, el enfoque histórico hermenéutico y el tipo etnográfico; se realizó el trabajo de campo mediante la técnica de entrevista no estructurada, aplicada a docentes universitarios adscritos a los programas de pregrado de psicología de la Universidad Mariana y la Institución Universitaria CESMAG de la ciudad de Pasto, Nariño, Colombia.

Resultados. Se sintetizan en una matriz de categorías que se construyó con base en la información recolectada. El análisis de la información se hizo a partir de la técnica de la triangulación.

Discusión. Se divide y se analiza la información obtenida en tres apartados, siendo el primero, las competencias docentes como un medio para la transmisión de saberes; el segundo, competencias docentes como habilidades personales y sociales $y$, el tercero, las competencias docentes como habilidades para la formación integral.
Conclusiones. Es necesario que los docentes realicen capacitaciones en el enfoque por competencias, con la finalidad de que refuercen sus conocimientos sobre esta temática y puedan orientar una educación que responda a las necesidades del siglo XXI.

Palabras clave: Concepciones, competencias, competencias docentes, formación, psicología.

\section{Abstract}

Objective. This article is the product of the research obtained as a result of the thesis "Teaching competencies for professors of undergraduate psychology programs". It aims to determine the conception of teaching competences of teachers of undergraduate psychology programs.

Methodology The research was guided by the qualitative research paradigm, the historical hermeneutical approach and the ethnographic model; field work was done using unstructured interviews, applied to university professors assigned to the undergraduate psychology programs of the Mariana University and the CESMAG University in the city of Pasto, Nariño, Colombia.

The results. Were synthesized in a matrix of categories based on the information collected. Information was analyzed through the triangulation technique. The 
information obtained was divided and analyzed in three sections, the first being the teaching competences as a means for the transmission of knowledge; the second, teaching competences as personal and social skills and the third, the teaching competences as abilities for integral formation.

Conclusions. It was concluded that it is necessary for teachers to carry out training in the competency-based approach, with the aim of reinforcing their knowledge on this topic that can guide an education that responds to the needs of the 21 st century.

Keywords: Conceptions, competencies, teaching competences, training, psychology.

\section{Introducción}

Sobre el tema de competencias docentes, objeto de la presente investigación, son varios los autores e investigadores que construyen conocimiento, como Morales y Cabrera (2012) quienes consideran que en el ejercicio del docente que trabaja en el ámbito universitario, independientemente de la profesión que enseñe o profese, debe tener competencias básicas en lo que concierne a su actuación como educador. Tomando como referencia a Delors (1996) en su propuesta acerca de los pilares de las competencias, el ser, el conocer, el hacer y el convivir es posible extrapolar estos aspectos al ejercicio docente; primero, competencias profesionales del saber ser, autoformación, desarrollo de valores y virtudes; segundo, competencias del saber conocer; formación inicial, educación continua, especialización, posgrados, entre otros; tercero, competencias del saber hacer, reflexivo, creativo, consciente de las necesidades del contexto y de sus estudiantes; cuarto, competencias del saber convivir, tiene que ver con la capacidad del docente para compartir su conocimiento y experiencia mediante la socialización y divulgación de este, a través de publicaciones, de su participación como conferencista o ponente en seminarios, congresos, encuentros, eventos y sistemas masivos de información y comunicación.

Tejada (2009) argumenta que el docente debe tener conocimiento del proceso de aprendizaje del estudiante, tanto en contextos naturales como académicos; planificación de la enseñanza e interacción didáctica, gestión de la interacción didáctica y de las relaciones con los estudiantes; control, evaluación y regulación del propio ejercicio docente y del aprendizaje; debe estar al tanto de las normas legales e institucionales bajo las cuales se amparan los derechos y deberes del profesor y el estudiante, mediante la capacidad para identificar las necesidades y los objetivos de innovación en la docencia y de su propia formación.

En relación con lo anterior, el MEN (2015) en el Decreto 1075 de 2015, por medio del cual se expide el Decreto Reglamentario Único del Sector Educación, específicamente el apartado 5, en el cual se da la reglamentación de la educación superior; menciona que, una institución de educación superior debe poseer un cuerpo docente que garantice el cumplimiento de los objetivos de la formación; es decir, es fundamental que los profesores tengan las competencias docentes necesarias para realizar con idoneidad su ejercicio profesional, siendo este, el aspecto principal por el que vela esta investigación.

Así mismo, en el Decreto 2566 de 2003, por el cual se establecen las condiciones mínimas de calidad y demás requisitos para el ofrecimiento y desarrollo de programas académicos de educación superior y se dictan otras disposiciones del MEN (2003), en su artículo 9, refiere que el personal académico debe contar con formación académica y pedagógica, que les permita desarrollar satisfactoriamente sus labores como profesores de educación superior. En coherencia con esto, el Consejo Nacional de Acreditación - CNA (2013) indica que los sistemas de pregrado deben tener políticas respectivas a la actualización del conocimiento del profesorado; tanto a nivel académico como pedagógico, relacionados con la metodología de enseñanza del programa; además, deben contar con el acompañamiento de expertos para la cualificación de la labor pedagógica de los profesores y su desarrollo integral. 


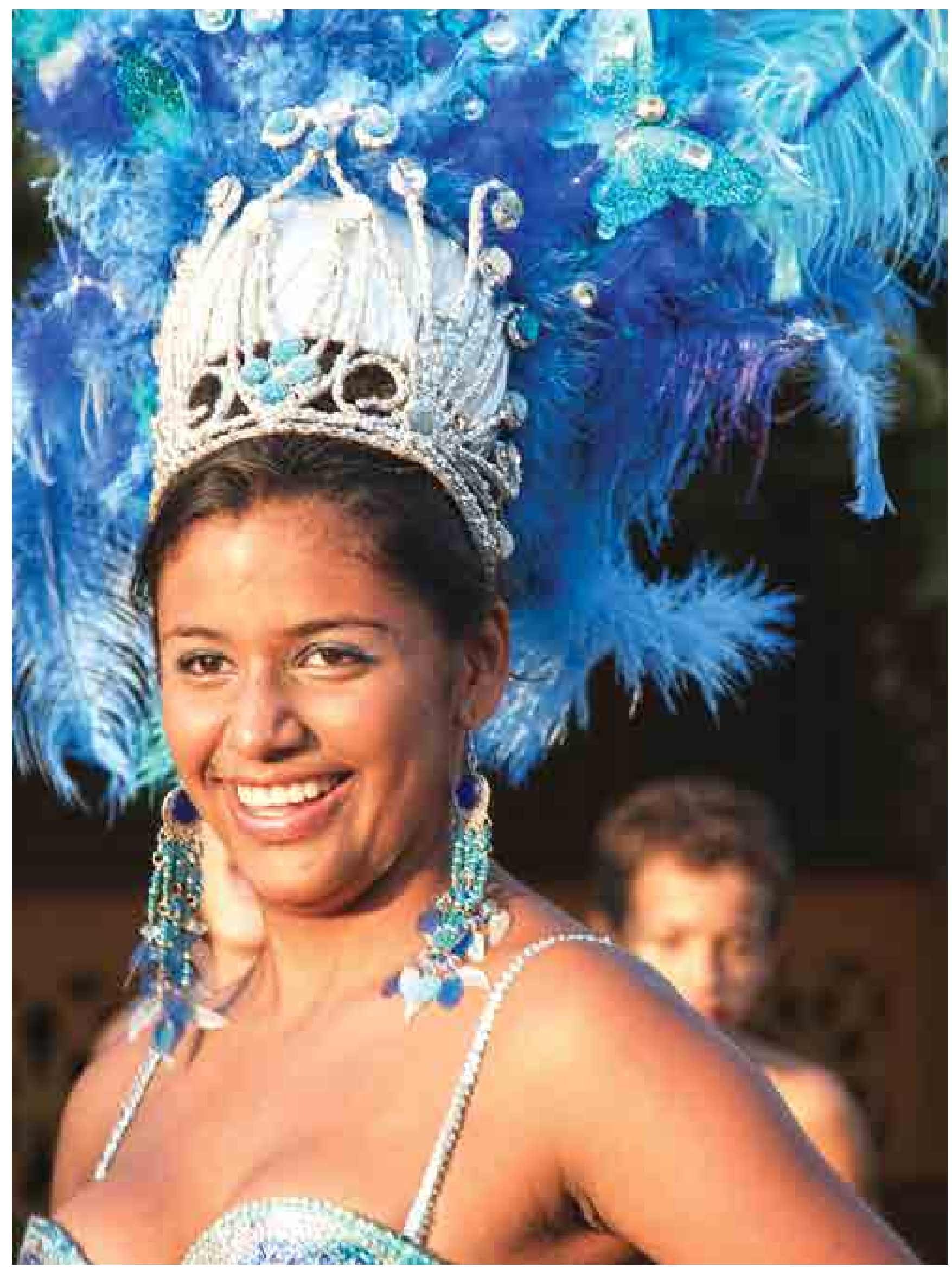


Según lo mencionado en estos decretos, se destaca que todo programa de educación superior debe tener vinculados docentes con las competencias necesarias para orientar la formación profesional de manera integral en su disciplina; por tanto, debe haber expertos en el área de trabajo; es decir, personas que tengan las capacidades y la cualificación suficiente para determinar las competencias que un docente debe poseer para realizar con eficiencia su ejercicio docente en la formación de profesionales, una responsabilidad social de vital importancia, que según Hernández, Alvarado y Luna (2015) orienta la creación, el desarrollo y la innovación del conocimiento para lograr impactos particulares en la educación y el la sociedad, implicando un compromiso muy particular del docente universitario con las competencias docentes necesarias para que su quehacer redunde en la formación del ser humano, del ciudadano y el profesional, en esta investigación en particular en el área de la psicología.

Bozu (2010) señala otra perspectiva sobre lo que implica un buen ejercicio docente o una docencia de calidad, refiriendo que son necesarias las competencias para el quehacer como docente, para el cual es necesario abarcar los factores que la condicionan y los atributos que la caracterizan, entre estos se pueden encontrar factores institucionales, como son: estructuras organizativas, coordinación interdepartamental, centros de recursos multimedia, grupos de apoyo, recursos tecnológicos y ofertas formativas constantes. Del ejercicio individual del docente se pueden considerar como indicadores de pertinencia: el desarrollo de un programa de calidad de la asignatura, la excelencia de la calidad de los recursos didácticos empleados, el dominio de los conocimientos de la materia que se imparte, eficiencia en la capacidad argumentativa y expositiva, claridad en los procesos evaluativos, aplicabilidad de los contenidos en la práctica y en la experiencia profesional, conocimiento de las necesidades y las carencias formativas del alumnado y, por último, entrega, dedicación y entusiasmo personal.
Bragós (2012), por su parte, resalta tres grandes grupos de competencias transversales para los docentes, entre las que se señalan las competencias que implican el conocimiento teórico o disciplinar de la profesión; competencias de razonamiento; atributos y habilidades personales como profesionales y las habilidades interpersonales.

De otra parte, cabe resaltar la investigación de Giné (2008) sobre las consideraciones de los estudiantes de IES acerca del ejercicio docente, quienes destacan que el profesorado ha de ser capaz de emplear estrategias didácticas que posibiliten a los estudiantes desarrollar competencias profesionales para resolver problemas contextuales, enriquecidas de conocimientos actualizados y pertinentes a las necesidades y demandas de la profesión y de la sociedad, que comprometan al estudiante con su aprendizaje mediante procesos reflexivos y críticos para enfrentarse de manera efectiva a nuevos retos.

\section{Metodología}

Esta investigación se trabajó con un paradigma cualitativo, debido a que este estudio se acerca a una realidad social para explorarla, describirla y analizarla, basándose según Bonilla y Rodríguez (1997) en la percepción subjetiva que tienen los individuos como fuente de información que permita construir la realidad; ya que, como lo menciona Martínez (2011), existe una diversidad de realidades que se crean a partir de la interacción del sujeto con el entorno social en el cual vive, por lo que no puede hablarse de una sola verdad, ya que esta nace de la significación de las diferentes percepciones que los individuos obtienen de las múltiples situaciones en que se desenvuelven.

En el área de la educación, la mejor forma de llegar a la producción de conocimiento, siempre será a partir del conocer, comprender e interpretar la realidad ya existente, la cual si se aborda desde una visión cualitativa del mundo, permite interpretar con profundidad y detalle lo que su- 
cede con un objeto de estudio, que si bien parte de la realidad, en la interpretación el sujeto investigador hace parte del fenómeno u objeto que está estudiando (Cerda, 2011). Permitiendo aproximarse a la realidad no solo desde un punto de vista objetivo, sino también, subjetivo.

\section{Enfoque}

Se orientó la investigación desde la hermenéutica, que pretende llegar a la comprensión de los hechos a través de la interpretación de los sentidos, los cuales solamente se pueden estructurar a través de aquellos que obran en el contexto determinado que se va a estudiar (Hoyos, 2011).

\section{Tipo de investigación}

La investigación se desarrolló siguiendo los lineamientos de la etnografía, puesto que tiene como fin analizar las prácticas de un grupo de personas en un contexto específico o de individuos que por su estilo de vida son semejantes (Angrosino, 2012 \& Martínez, 2011); de modo que, al desarrollarse la investigación con docentes de programas de pregrado de psicología de las universidades que hacen parte del contexto local, se logró develar sus concepciones acerca de lo que implican para el ejercicio docente, las denominadas competencias docentes.

\section{Población}

El trabajo se llevó a cabo con la participación de docentes que pertenecen a los programas de psicología de la Universidad Mariana y la Institución Universitaria Cesmag de la ciudad de Pasto, en el departamento de Nariño, Colombia. La muestra estuvo conformada por 13 docentes psicólogos de profesión, que voluntariamente decidieron participar en la investigación; ocho de ellos con formación culminada o en proceso en el nivel de maestría y cinco especialistas; de los cuales cuatro docentes son posgraduados en programas del campo de la educación, con vinculación como docente, superior a tres años.

\section{Técnicas de recolección e interpretación de la información}

Con la intención de dar cumplimiento a los objetivos planteados en este proyecto investigativo, se escogió la entrevista como técnica de recolección de información, debido a que permite recolectar información de un grupo de individuos, bien sea conocer características de la población, opiniones o actitudes sobre el tema, enfocándose en las categorías del estudio (Calvache, 2005). La información se interpretó a través de la técnica de triangulación, empleando diferentes visiones sobre la realidad del hecho social objeto de la investigación, siendo estos, la teoría previamente revisada sobre el tema, la información recolectada y el punto de vista del investigador como constructor principal de los hechos (Bericat, 1998).

\section{Resultados}

\section{Las competencias docentes: una mirada desde el docente universitario}

A continuación se presentan los resultados obtenidos a través de la entrevista, acerca de las concepciones que tienen los profesores de los programas de psicología sobre lo que son las competencias docentes. La pregunta base: ¿Qué son las competencias docentes?, cuyos resultados se expresan por institución participante.

Las competencias docentes desde la mirada de los docentes Universidad Mariana

Son las capacidades y actitudes que tenemos los profesores para desempeñar el cargo de docente como tal, en este campo hay varias competencias, como las cognitivas, actitudinales, investigativas, relacionales, las competencias del ser. Esta respuesta confirma que el docente conoce la existencia de las competencias docentes, siendo consciente de la necesidad de lograrlas para mejorar su desempeño. 
Refieren que las competencias docentes tienen que ver con la capacidad de articular el saber, el ser y hacer, y aplicarlas en la construcción y la transmisión del conocimiento. Esta respuesta se aproxima a la definición general de competencia, sin embargo, señala dos elementos básicos, la construcción y la transmisión del conocimiento; esta última lo ubica en una docencia transmisionista, que lo aleja del verdadero sentido de la formación de profesionales por competencias.

Los docentes de los programas de psicología consideran que las competencias docentes son las habilidades para transmitir el conocimiento. Esta respuesta es propia de un docente que no tiene formación pedagógica y tampoco ha sido cualificado en el enfoque de formación profesional por competencias; es la razón por la cual su concepción sobre el término no corresponde a lo contemplado en la teoría sobre el mismo.

Señalan que competencias docentes son las capacidades, habilidades, conocimientos, a partir de los cuales se puede generar un diálogo de saberes y de construcción de juicios críticos; como cuestionar lo existente y dar evidencia de fuentes de conocimiento que lo validen. La concepción del profesor tiene elementos importantes de las competencias docentes, destacando la construcción de criterios y juicios críticos, finalidad fundante de las competencias en el ejercicio docente al formar profesionales; sin embargo, hace falta tener en cuenta elementos del saber ser y del saber convivir, pues se debe considerar que la formación del psicólogo es integral.

Argumentan los docentes, que las competencias docentes no son algo claro, en los manuales de funciones aparecen como funciones laborales, pero no son competencias como tal, deberían estar enfocadas a la docencia, a la proyección social, a la investigación, a los conocimiento y a la práctica. El docente no centra su respuesta en la concepción de las competen- cias docentes, simplemente hace ciertas críticas muy generales, dando la idea de desconocer sobre el tema en el que se enfoca la pregunta.

La competencia en educación es un término generalizado, centrado en el quehacer docente pedagógico, es el desarrollo de la habilidad dentro del contexto escolar. En esta concepción se demarcan las competencias docentes únicamente hacia lo pedagógico, que si bien es una parte importante de ellas, es una concepción reducida o limitada.

Razonan sobre las competencias docentes como las capacidades pedagógicas y disciplinares para generar procesos de enseñanza aprendizaje con los educandos. Relacionan las competencias docentes con dos aspectos, lo pedagógico y lo disciplinar; es decir, el saber y el hacer del docente, relación importante para la formación de los profesionales, pero esta formación ha de ser integral, desde las distintas dimensiones del ser humano; por tanto, le hace falta al profesor asumir en su quehacer elementos del saber ser y el saber convivir para formar integralmente.

Definen las competencias docentes como las directrices que orientan el quehacer y el ejercicio profesional de la docencia universitaria. La limitada respuesta ofrecida por el docente deja claridad que no tiene conocimientos sobre este tema, ni interés por este.

Las competencias docentes para los docentes de la Institución Universitaria Cesmag

La concepción sobre competencias docentes en la educación se centra en un conjunto de habilidades y destrezas que los docentes han logrado desarrollar para favorecer el ejercicio de transmisión de conocimientos en la formación de estudiantes. Los docentes vinculan competencias docentes con una práctica desde un enfoque transmisionista y disciplinar, dejando de lado el componente humano $y$, por tanto, las competencias del saber y el saber convivir tan importantes en la actualidad educativa. 


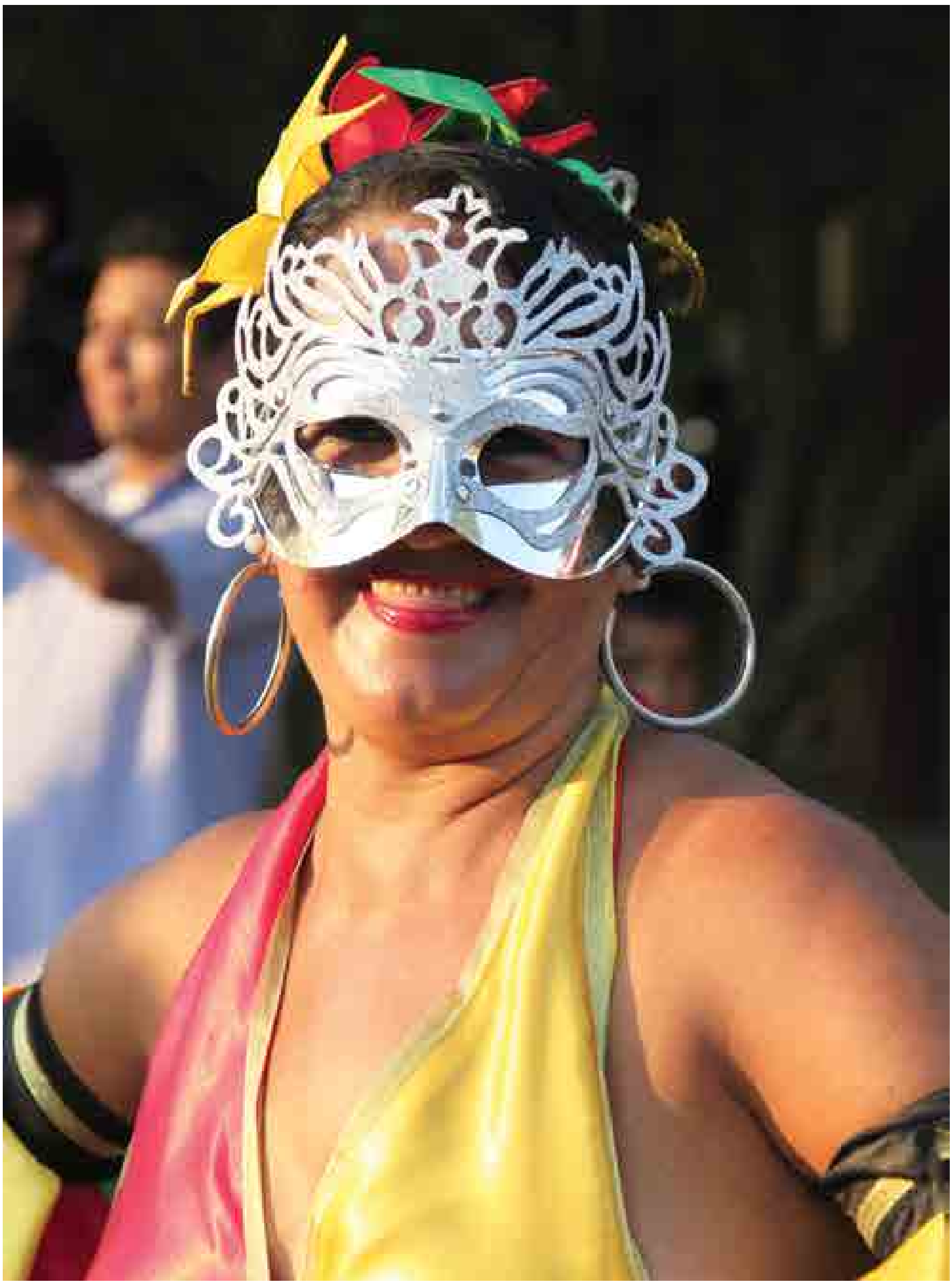


Son las habilidades las herramientas y las estrategias que tiene el docente universitario para poder segmentar lo que debe hacer con los alumnos; las competencias docentes es con lo que se transmite los conocimientos del docente al alumno, para que después puedan emplearlos en los diferentes contextos a los que tengan que enfrentarse. Prima una concepción transmisionista, pero tiene en cuenta los contextos de acción del futuro profesional.

Son las habilidades que el docente tiene en relación con su labor y con la misión de transmitir el conocimiento, el docente hace y traduce el conocimiento para el estudiante a través de habilidades comunicativas, empáticas e incluso de hacer del conocimiento algo amable para el estudiante. Se evidencia una acepción de tipo tradicionalista en la educación, no obstante, refiere aspectos concernientes a las competencias del saber ser y el saber convivir; aunque, las enfoca hacia la formación disciplinar.

Las competencias docentes son lo que debe tener el docente para ser idóneo, es decir, debe conocer y manejar las temáticas y la conducción de las asignaturas. El docente hace alusión a la idoneidad, relacionándola con la formación profesional o disciplinar, ignorando otros aspectos afines con la formación integral, tanto propia como de los educandos.

Las competencias docentes son las habilidades, capacidades y actitudes para desarrollar una actividad, la actividad de la docencia, para llevar al espacio académico su propia experiencia e interacción, para analizar y dirigir procesos de discusión que le permita al estudiante desarrollar sus propias competencias en tres dimensiones. El docente refiere diversos aspectos relacionados con el saber, como la experiencia, no obstante, las enfoca hacia la labor formativa que hace parte de su labor profesional; sin embargo, no toma en consideración aspectos que están relacionados con las competencias del saber ser y el saber convivir.

\section{Discusión}

Es necesario aclarar el concepto principal que se aborda en el artículo, para Guzmán y Marín (2011) las competencias docentes pueden definirse como aquellas competencias profesionales del docente que le permiten realizar una adecuada interacción social con los diversos contextos y situaciones que implica la práctica de la labor educativa; por tanto, puede considerarse que este concepto alude a las habilidades que un educador adquiere y desarrolla con la intención de aplicarla tanto dentro como fuera del aula de clase. Lo antes enunciado permite realizar procesos de orientación profesional a los educandos de manera integral, a través de estos procesos se aborden todas las dimensiones que hacen parte del ser humano tales como la afectiva, intelectual, social, política, biológica, transcendental, entre otras.

\section{Competencias docentes como un medio para la transmisión de saberes}

Frente a esta categoría, se encontró que diez de los trece educadores que fueron entrevistados tienen acepciones que se limitan a los procesos formativos; es decir, tienen la concepción de las competencias docentes como un conjunto de capacidades y habilidades que les permiten realizar un mejor ejercicio para el proceso de enseñanza, enfocándose netamente en la transmisión de contenidos temáticos, es decir, desde una visión netamente académica. Al respecto, señala Giné (2008) que el profesorado debe tener conocimientos disciplinares, pero además, conocimientos que le posibiliten emplear diferentes estrategias didácticas y metodológicas, que faciliten la orientación del aprendizaje y la formación profesional del estudiantado; lo que por un lado, es un trabajo que emplea una gama de capacidades por parte del educador, quien debe saber aplicarlas de manera creativa para poder llegar a sus estudiantes de forma tal, que despierte en ellos un verdadero interés por los diferentes saberes. Complementa Tobón (2013) que es necesario 
que los psicólogos sean formados no solo en la cuestión disciplinar, sino también y, principalmente, en lo que guarda relación con su desarrollo humano y el saber vivir en sociedad, concepción que posee mutua relación con el saber ser y el saber convivir.

En este sentido, para los profesores entrevistados, las competencias docentes son habilidades de tipo pedagógico y disciplinar que les permite brindar una transmisión de conocimientos eficaz; más, como se menciona anteriormente, el enfoque de las competencias en la educación superior busca no solo la formación académica, sino una serie de aspectos multidimensionales que permiten formación integral del estudiante, que responda a las necesidades del ser humano (Sabogal, 2009); siendo esto coherente con lo que se espera lograr a través del enfoque por competencias, el cual difiere de la una transmisión simple de conocimientos, de modo que, los educadores al limitar sus acepciones únicamente a este aspecto transmisionista del conocimiento dejan de lado o ignoran otros que solamente fueron tomados en consideración por dos de los docentes que refirieron, componentes como el saber ser y el saber convivir, mencionando que una de las competencias docentes es ser y dar ejemplo en lo que se hace; denotándose interés por la formación desde la propia experiencia, la cual apunta hacia la formación de profesionales integrales. Lo anterior es coherente con lo mencionado por Bragós (2012), quien dice que existen tres grandes grupos de competencias transversales fundamentales para apoyar el quehacer de cada uno de los docentes universitarios, el conocimiento de la disciplina objeto de su desarrollo como docente, las habilidades personales y pedagógicas para orientar la formación de sus estudiantes y las capacidades interpersonales para interactuar con el medio.

Ahora, es pertinente resaltar que los docentes destacan la importancia que tienen las competencias docentes, nueve de los 13 educadores consideran que estas permiten al edu- cador realizar un mejor ejercicio pedagógico para la transmisión de los conocimientos a los estudiantes; frente a esto, es necesario aclarar que las competencias o las competencias docentes no buscan en ninguna medida mejorar esta actividad correspondiente a la educación bancaria (Freire, 2008); puesto que, lo que se propende a través de este enfoque es el aprendizaje para toda la vida (Delors, 1996) y como lo señala Tobón (2013) una educación integral en todos los ámbitos del ser humano.

\section{Competencias docentes como habilidades personales y sociales}

Cuatro docentes refieren acepciones particulares frente a la importancia que tienen las competencias docentes; siendo estas; primera, que su utilidad recae en que al ser estas adquiridas y empleadas de manera adecuada, permiten generar ambientes de aprendizaje ameno para los estudiantes, convirtiéndose en un canal eficaz de comunicación en la educación, competencia docente fundamental que es parte de uno de los factores que según Bragós (2012) y Abadía et al. (2015) un docente debe tener en su propio marco o gama de competencias; puesto que, la comunicación efectiva y la capacidad para establecer buenas relaciones interpersonales son de las más valoradas por los estudiantes de psicología; ya que permiten generar un mayor sentimiento de confort en los espacios académicos; otros autores que resaltan la importancia de la buena comunicación son Domínguez y Medina (2010), quienes consideran que esta es una de las competencias docentes que posee una mayor incidencia en el campo educativo.

\section{Las competencias docentes como habilidades para la formación integral}

La segunda concepción, que fue dada por dos de los trece docentes, resalta que la verdadera utilidad de las competencias docentes es que permiten destacar el respeto por la diferencia y por el ser humano; es decir, más 


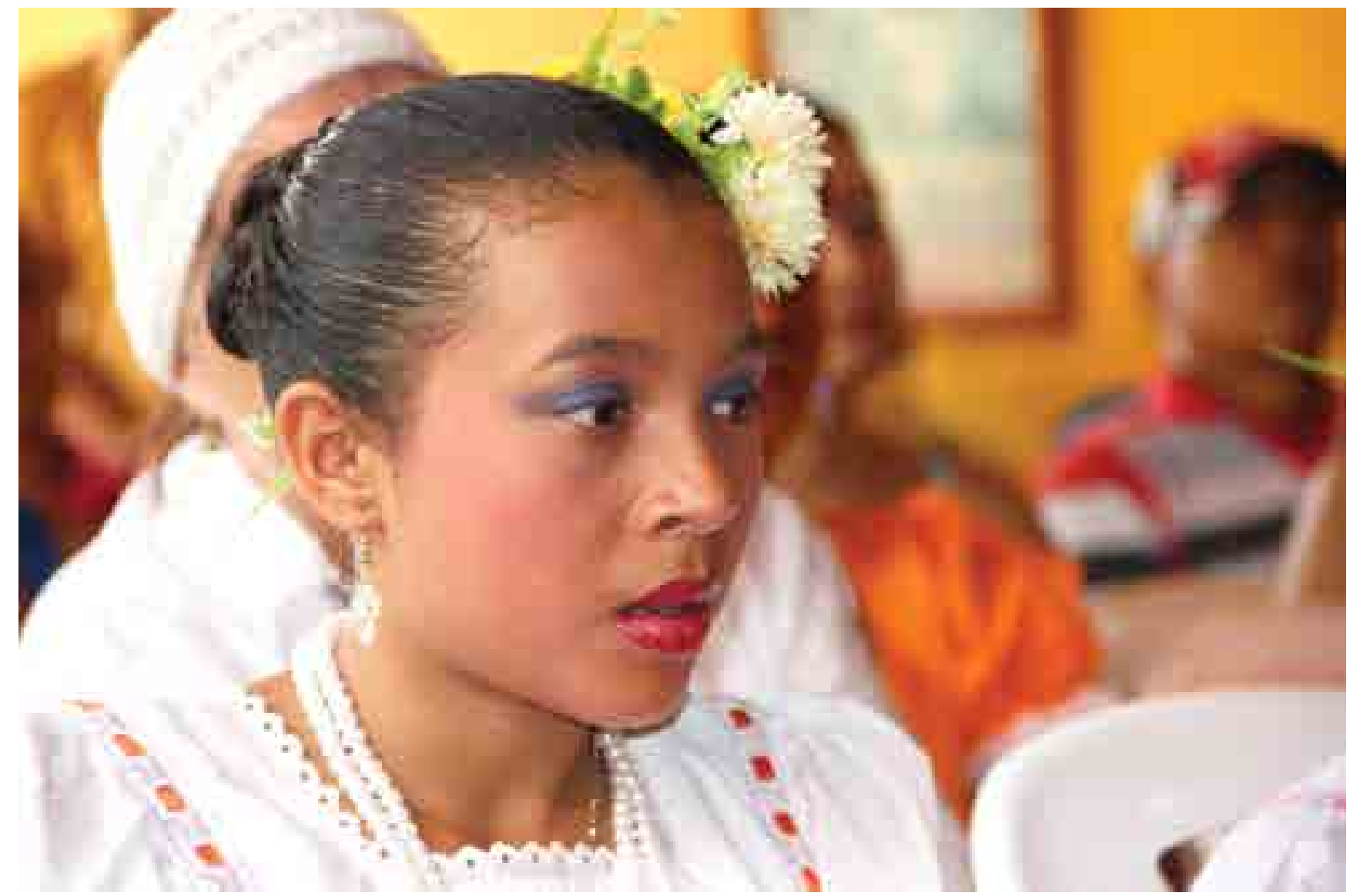

que enfocarse en los contenidos teóricos, es de importancia enseñar u orientar sobre cómo contribuir de manera positiva en las diferentes dimensiones en las que se desarrolla una persona; entre las cuales, a decir de Sabogal (2009), están lo afectivo, lo social, lo lúdico, lo político, entre otros. Además, se resalta la validez de este argumento, siguiendo lo dicho por Biesta (2012), quien refiere que factores como la formación en valores y la inclusión social son aspectos que fortalecen en gran medida los procesos de aprendizaje de la formación con visión integral. Esto a su vez, guarda relación principalmente con la argumentación de Delors (1996) acerca del pilar de la educación, referido al saber convivir, del que hacen parte todos aquellos aspectos que permiten alcanzar la comprensión, la aceptación del pluralismo y la creación de ambientes de paz.

En relación con lo anterior, los profesores resaltan, que las competencias docentes permi- ten obtener una perspectiva adecuada sobre lo que es la educación superior y la formación profesional, permitiendo desarrollar una vocación por esta, siendo este último concepto una de las competencias que para Domínguez y Medina (2010) hace parte de las visiones fundamentales que debe tener un docente de educación superior; ya que le permite generar una identidad profesional y un mayor interés por los procesos de formación académica y humana que en su función laboral debe orientar.

\section{Conclusiones}

Las concepciones sobre competencias docentes que subyacen en el desempeño de los profesores de programas de psicología de las dos instituciones de educación superior que participaron en esta investigación, tienen que ver con un concepto de competencia ligado al campo empresarial, donde la competencia tiene que ver fundamentalmente con el saber 
y el hacer; por ello la relacionan con las capacidades y conocimientos de la temática que aborda la disciplina objeto de su desempeño docente, orientadas dichas capacidades a fortalecer la transmisión de conocimientos a sus estudiantes, para que estos a su vez adquieran las habilidades necesarias para que sean capaces de aplicarlas en contextos determinados; descartando elementos fundamentales como el desarrollo del ser de la persona y su relación con la sociedad; es decir, dentro de su concepción de competencias docentes no relacionan los conocimientos, habilidades, destrezas y valores que debe poseer un docente para impactar en una formación integral del psicólogo que requiere actualmente el mundo del siglo XXI en su globalidad y complejidad.

Es evidente que los docentes que participaron en la investigación son profesionales de la psicología, expertos en su área y disciplina objeto de su quehacer docente en los programas académicos, pero, que carecen de la formación pedagógica necesaria para acercarse a la realización de esta importante labor desde las competencias docentes requeridas, es por ello que, sus concepciones sobre el tema sean vagas, dispersas e incompletas, según lo deseado para ejercer esta profesión. Sin embargo, cabe resaltar que en sus concepciones detallan elementos importantes que forman parte de las competencias docentes, entre ellos: la comunicación efectiva entre docente y estudiante, el ser ejemplo de vida ante sus alumnos, la educación en valores y el rescate de lo humano en la educación.

Siendo en la actualidad el enfoque por competencias la tendencia en la formación de profesionales del siglo XXI, se requiere que el profesor universitario, en este caso particularmente el profesor de programas de psicología, se cualifique y desarrolle las competencias docentes tanto transversales como específicas para optimizar su función en la formación integral del psicólogo; pero a la vez, sea capaz de asumir responsablemente concepciones perti- nentes sobre las competencias docentes en su quehacer; proyectando la verdadera finalidad de la educación desde prácticas que humanicen este campo, orientando la formación de los individuos que se encuentran inmersos en las instituciones de educación formalizada; lo que implica, que a través de la implementación de las competencias docentes se brinde orientación integral al estudiantado, que les permita crecer no solo a nivel académico, sino también, como ciudadanos proactivos capaces de transformar la realidad existente en la sociedad.

\section{Referencias}

Abadía, A. et al. (2015). Competencias del buen docente universitario. Opinión de los estudiantes. REDU, 13(2), 363-390.

Angrosino, M. (2012). Etnografía y observación participante en investigación cualitativa. Madrid: Ediciones Morata.

Beneitone, P. et al. (2007). Reflexiones y perspectivas de la educación superior en América Latina. Informe final proyecto Tuning - América Latina 2004-2007. Recuperado de file:///C:/Users/Andres/Downloads/LIBRO_TUNING_ AMERICA_LATINA_version_final_espanol\%20(1).pdf

Bericat, E. (1998). La integración de los métodos cuantitativo y cualitativo en la investigación social. Barcelona: Ariel.

Biesta, G. (2012). The future of teacher education: Evidence, competence or wisdom? ROSE Research on Steiner Education, 3(1), 8-21.

Bonilla, C., \& Rodríguez, S. (1997). Más allá del dilema de los métodos la investigación en ciencias sociales. Bogotá: Ediciones Uniandes.

Bozu, Z. (2010). Los jóvenes profesores universitarios en el contexto actual de la enseñanza universitaria. Claves y controversias. Revista Iberoamericana de Educación, 51, 3-25.

Bragós, R. (2012). Las competencias del profesorado en el entorno CDIO. REDU Revista de Docencia Universitaria, 10(2), 57-73.

Calvache, J. (2005). La investigación una alternativa pedagógica y didáctica en la formación profesional. San Juan de Pasto. CEPUN Centro de Publicaciones Universidad de Nariño.

Cerda, H. (2011). Los elementos de la investigación cómo reconocerlos, diseñarlos y construirlos. Bogotá: Editorial Magisterio.

Consejo Nacional de Acreditación CNA (2013). Lineamientos para la acreditación de programas de pregrado. Recuperado de http://www.cna.gov.co/1741/articles-186359_ pregrado_2013.pdf.

Delors, J. (1996). La educación encierra un tesoro. Informe a la UNESCO de la Comisión Internacional sobre la educación para el siglo XXI presidiada por Jaques Delors. Madrid, España: Santilla Ediciones UNESCO. 
Domínguez, M., y Medina, M. (2010). Evaluación de las competencias docentes. Innovación Educativa, 10(53), 19-41.

Echeverria, P. (2010). El papel de la docencia universitaria en la formación inicial de profesores. Calidad en la Educación, 32, 150-165.

Freire, P. (2008). Paulo Freire y la pedagogía del oprimido. Rhela, 10, 57-72

Giné, N. (2008). Cómo mejorar la docencia universitaria: el punto de vista del estudiantado. Revista Complutense de Educación, 20(1), 117-134.

Guzmán, l., y Marín, R. (2011). La competencia y las competencias docentes: reflexiones sobre el concepto y la evaluación. REIFOP, 14(1), 151-163.

Hernández, I.; Alvarado, J., y Luna, M. (2015). Creatividad e innovación: competencias genéricas o transversales en la formación profesional. Revista Virtual Universidad Católica del Norte, 44, 135-151.

Hoyos, G. (2011). Los intereses de la vida cotidiana y las ciencias (Kant, Husserl, Habermas). Bogotá D.C., Colombia: Empresa Editorial Universidad Nacional de Colombia.

Martínez, J. (2011). Metodologías de la investigación cualitativa. Silogismo más que Conceptos, 8(1), 27-38.
Ministerio de Educación Nacional (2003). Decreto 2566 de septiembre 10 de 2003. Por el cual se establecen las condiciones mínimas de calidad y demás requisitos para el ofrecimiento y desarrollo de programas académicos de educación superior y se dictan otras disposiciones. Recuperado de http://www.mineducacion.gov.co/1621/ articles-86425_Archivo_pdf.pdf

Ministerio de Educación Nacional (2015). “Por el cual se adiciona el Decreto 1075 de 2015 Único Reglamentario del Sector Educación, para reglamentar la Ley 1740 de 2014". Recuperado de http://www.mineducacion.gov. co/1759/articles-353594_recurso_1.pdf

Morales, R., y Cabrera, J. (2012). Competencias docentes transversales, el método de selección MiZona-CDT. REDU Revista de Docencia Universitaria, 10(2), 75-101.

Sabogal, J. (2009). Desarrollo humano multidimensional. Facultad de Ciencias Económicas y Administrativas - FACEA, Universidad de Nariño. Pasto. Editorial Universitaria.

Tejada, F. (2009). Competencias docentes. Profesorado Revista de Currículum y Formación del Profesorado, 13(2), 1-15.

Tobón, S. (2013). Formación integral y competencias: pensamiento complejo, currículo, didáctica y evaluación. (4a ed.). Bogotá: Ecoe Ediciones Ltda. 